With EMA's opinion, the World Health Organization (WHO) will now convene its Strategic Advisory Group of Experts on Immunization and the Malaria Policy Advisory Committee to make a preliminary recommendation on whether and how to use the vaccine by the end of October; a final WHO policy recommendation is expected by November. Gitahi explains that malaria-affected countries then must provide national regulatory approval, which may be expedited through a WHO recommendation.

Procuring the vaccine is also a challenge for low-income countries. GlaxoSmithKline has promised to make the vaccine available at a reduced price although it hasn't set that price yet that would cover manufacturing costs plus a small return. Its profits will go back into research on vaccines for malaria and other tropical diseases. In addition, it will donate 12.5 million doses to PATH, an international nonprofit health organization that was a partner in developing the vaccine.

Careful planning of vaccine implementation in communities is the key to success, agree Gitani and Greenwood. Both are concerned that the introduction of a vaccine could lead to complacence about other prevention measures.

"Once the vaccine is available, governments and organizations like ours have to be very careful about the rollout," says Gitahi. "It should not be about the vaccine but about a two- or three-step 'this-is-how-you-preventmalaria' program. If you roll out [the vaccine] singularly, you could lose the gains that have been made with insecticidal nets."

Greenwood points out that, similarly, "in some of the HIV vaccine trials there was concern that people would stop using condoms, but that didn't happen." He thinks vaccine implementation requires "a proper community education program" that clearly informs those at risk, "Don't stop using your bed net."

Gitani hopes that use of the vaccine will lead to continued vaccine development. "Following precedent in medicine and research, once there is one, and once it is field-tested, the challenges are easier to see. In a few years there will probably be vaccines that are improvements over this one." - Carolyn Brown, Ottawa, Ont.

CMAJ 2015. DOI:10.1503/cmaj.109-5132

\title{
Growing the evidence base for medical cannabis
}

A necdotal reports of efficacy from patients who use medical marijuana aren't enough to convince many physicians that cannabis is a viable therapeutic option, but new industry-funded research in Canada may bring some science to the situation.

Some of Canada's 25 or so licensed producers under the federal medical marijuana program are investing in research to add credibility to their products. As of June 2015, Health Canada had approved six clinical trials involving patients who use dried cannabis; several others are pending approval. There are also a few large-scale observational studies, including a provincewide one in Quebec.

Medicinal marijuana is used for an array of symptoms and conditions, including multiple sclerosis, osteoarthritis, cancer and anxiety. It's up to the discretion of the physician to prescribe access, but the problem is the lack of rigorous guidelines based on scientific evidence.

Many licensed producers have been collecting patient data, and some are now partnering with university-based researchers to conduct large-scale observational studies; one wants to enroll 1000 patients, another is aiming for 3000 .

This research is possible, in part, because the growing industry now wants to show efficacy for its lucrative products - and is willing to pony up the cash to obtain evidence. Also, there are many more strains of cannabis to be tested than even two years ago. Prior to 2013, there vaporizer, as well as a placebo stripped of the two main active compounds, tetrahydrocannabinol and cannabidiol.

Leading the trial is Zach Walsh, the codirector for the Centre for the Advancement of Psychological Science and Law at UBC, who plans to recruit 40 patients who have served in the military or as first responders, or have survived a sexual assault. He says existing

\section{"We are catching up with patients who have been leading the medical cannabis movement."}

was one government-approved producer and one strain of the plant. Now there are hundreds of strains.

Tilray, for example, has 55 strains in its \$30-million facility in Nanaimo, British Columbia. Three of those strains will be used at the University of British Columbia (UBC) in Kelowna for what may become Canada's first randomized clinical trial on the use of cannabis for posttraumatic stress disorder (PTSD). Tilray is providing $\$ 400000$ and the dried bud for patients to use with a treatments for a large number of people with PTSD are not effective, and many are already using cannabis to ease their symptoms. "We are catching up with patients who have been leading the medical cannabis movement."

Tilray is "in a unique position to be able to fund and support this kind of research in a way that hasn't happened in North America in the past," says Philippe Lucas, the company's vice president of patient research and services. Tilray is exploring other oppor- 


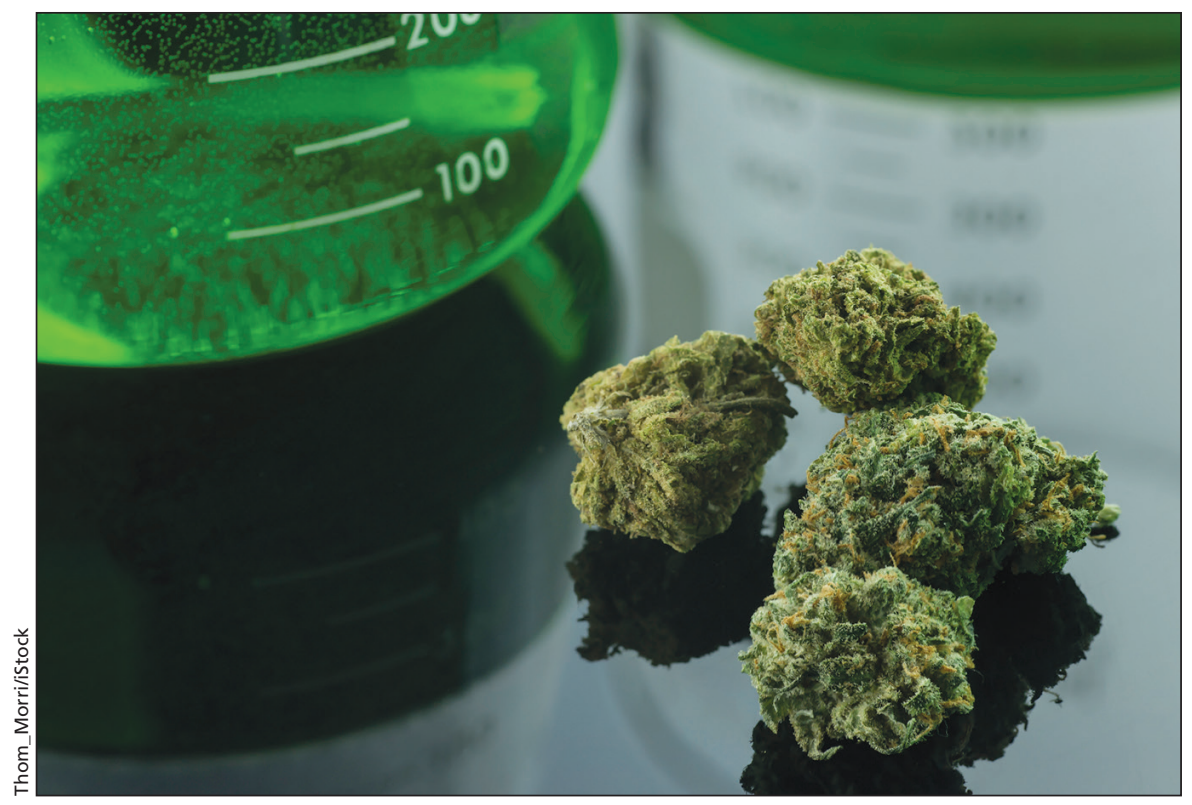

Licensed producers of cannabis are starting to invest in research.

tunities to provide "research-grade cannabis" for studies.

One of the eventual goals of the UBC study is to acquire Health Canada approval and an official drug identification number for a cannabis product that is shown to treat symptoms of PTSD. There are currently only two cannabinoid pharmaceutical drugs approved by Health Canada, but the raw form of the drug, either as a dried bud or oil derivative, has yet to garner approval as a medicine.

\section{Quebec's registry}

In 2014, Ottawa put physicians in the contentious position of prescribing access to an untested drug. Quebec's college of physicians and surgeons saw this is an opportunity to use these patients as the basis for a province-wide registry and study. "In Quebec, when you have to try a new medication or an experimental medication you can only do that through a research program," says Dr. Charles Bernard, CEO of the Collège des médecins du Québec.

The Quebec Cannabis Registry has arm's-length funding from three licensed producers: Bedrocan Canada, Mettrum Ltd. and Tweed Marijuana Inc., says Dr. Mark Ware, a pain medicine specialist at the Montreal General Hospital and the Montreal Neurological Institute who is leading the study. "The idea is if we're going to provide access we can at least learn something from it."
The vice president of communications and corporate affairs at Bedrocan, Cam Battley, says that companies like his are planning fairly rigorous clinical programs. "We need to have more evidence with respect to the potential benefits of cannabis as well as the risks and the side effects."

Ware hopes to recruit 2000-3000 patients over the next few years, depending on how many doctors participate in the 10-year observational study. Under the study parameters, the prescribing physician must monitor the effects of the drug by filling out a form detailing information about the disease or condition being treated, symptoms and the cannabis strain and quantity. They must then follow up with the patient every three months.

Ware is also leading a randomized controlled trial looking at vaporized cannabis for patients with osteoarthritis of the knee; he started recruiting patients in June. "We've heard a lot of anecdotal evidence from patients with osteoarthritis who report that they get benefit from using cannabis so we're putting this to the test," he says. This trial has arm'slength funding from Prairie Plant Systems Inc. and CanniMed Ltd.

Some researchers say the biggest challenges around studying cannabis are the lack of funding and the stigma. Licensed producers seem to be the only willing patrons, but Ware says that, like studies sponsored by pharmaceutical companies, such a funding relationship engenders a risk of perceived bias.

A few studies have found alternate funding - albeit still within the industry. In Ontario, a 1000-patient observational study is being supported by CanvasRx, a medical cannabis patient education and counselling service. Principal investigator Dr. Hance Clarke says the study is similar to the Quebec registry, except that the patient fills out the questionnaire. He hopes to eventually combine data with the Quebec registry but will also look at other outcomes of using cannabis, such as quality of life, sleep and mood.

Clarke, who is the director of the Pain Research Unit at the Toronto General Hospital, says collecting broad data is the first step before designing randomized controlled trials that study disease-specific indications. "You really need to have the comparison data to make sure we're sending people down the appropriate path."

A BC researcher is venturing down another research path. M-J Milloy, an infectious-disease epidemiologist with the British Columbia Centre for Excellence in HIV/AIDS, began an observational study in 1996 and found that patients with HIV who use cannabis daily had lower levels of the virus in their blood. The results were published in Drug and Alcohol Review in November 2014.

In June, the cannabis producer, National Green BioMed, offered Milloy and UBC a \$1-million grant for ongoing research in this area. "We were very lucky to receive support," says Milloy, adding that the funding is arm's length. "We have similar ideas with the need to grow the evidence base for medical marijuana."

The licensed producers - essentially Big Cannabis - are starting to take advantage of their unique position in the world. As Justin Dhaliwal, the CEO of BioMed, puts it: "At the end of the day, if it's a product that's going to improve the lives of Canadians, it's our duty to go ahead and spend the money in research to show that evidence." Shannon Lough, CMAJ

CMAJ 2015. DOI:10.1503/cmaj.109-5129 